\title{
La disputada gloria de Ronald Dworkin. Reflexiones a propósito de un homenaje póstumo* \\ Ronald Dworkin's Glory at Stake. Reflections on a Posthumous Tribute
}

\author{
Alfonso García Figueroa \\ Universidad de Castilla-La Mancha \\ alfonsoi.gfigueroa@uclm.es
}

Recibido / received: 13/09/2016

Aceptado / accepted: 18/09/2016

DOI: http://dx.doi.org/10.20318/eunomia.2016.3283

\section{Resumen}

Este trabajo explora las causas y razones del éxito e influencia de la teoría de Ronald Dworkin en la cultura jurídica en lengua española mediante el examen del conjunto de obras que, editadas por el Centro de Estudios Constitucionales, fueron publicadas con el título El legado de Dworkin a la filosofía del Derecho con ocasión del fallecimiento reciente de Dworkin.

\section{Palabras clave}

Dworkin, filosofía del Derecho, interpretación constitucional.

\section{Abstract}

This paper explores the causes and reasons of the success and preeminence of Ronald Dworkin's theory in the Spanish speaking legal culture by examining the set of works which have been edited by the Centro de Estudios Constitucionales after the title El legado de Dworkin a la filosofía del Derecho on the occasion of the recent Dworkin's death.

\section{Keywords}

Dworkin, Legal philosophy, constitutional intepretation.

SUMARIO. 1. Noticia obitual y editorial a mayor gloria de un jusfilósofo controvertido. 2. Una gloria sin paz. 3. ¿A qué se debe el éxito de Dworkin? 4. ¿Cómo aproximarse al legado de Dworkin? 5. Dworkin, ¿Un insospechado icono constitucional para gays y lesbianas? 6. La persuasiva doctrina Julia Roberts. 7. La filosofía

\footnotetext{
"J.M. Sauca (ed.), El legado de Dworkin a la filosofía del derecho. Tomando en serio el imperio del erizo, Centro de Estudios Políticos y Constitucionales, Madrid, 2015. A cambio de no citar al detalle el título de cada una de las contribuciones a ese volumen, indicaré la referencia a sus páginas en el cuerpo de mi artículo. Mi trabajo es un desarrollo más amplio del publicado en la Revista de Estudios Políticos, núm. 172, abril-junio 2016, pp. 257-265.
} 
moral del jusnaturalismo dworkiniano. 8. Coherencia metaética. 9. Conclusión.

1. Noticia obitual y editorial a mayor gloria de un jusfilósofo controvertido

A continuación desearía formular algunas reflexiones al hilo de El Legado de Dworkin a la filosofía del Derecho, un libro compuesto por José María Sauca con las contribuciones a las Jornadas celebradas los días 29 y 30 de octubre de 2013 en el propio Centro de Estudios Políticos y Constitucionales que lo edita. Su título es bien descriptivo de su contenido, pero su desenfadado subtítulo requiere de una inmediata aclaración al no iniciado, cuya perplejidad quizá se alivie al saber que "Tomando en serio el imperio del erizo" evoca tres obras centrales de la obra de Dworkin (p. 14): Los derechos en serio (Dworkin, 1984), El imperio de la justicia (Dworkin, 1992) y Justicia para erizos (Dworkin, 2014). Si la ocasión que dio lugar a aquellas jornadas, fue sensiblemente obitual -Dworkin había fallecido el 14 de febrero de aquel año-; la oportunidad del libro no admite discusión: Salvo sorpresas póstumas que no son del todo infrecuentes en nuestro pequeño mundo, el catálogo de obras de Dworkin se ha cerrado para siempre y casi ningún filósofo del Derecho puede ser insensible a esta circunstancia. Mientras los dworkinianos más fieles a buen seguro seguirán recreándose en sus balances para la posteridad, no podemos descartar que algún antidworkiniano fundamentalista celebre el punto final de la teoría. Sea como fuere y por más que se duelan sus críticos más feroces, nadie podrá ya negarle a Dworkin su lugar en la historia de la filosofía jurídica. Quiérase o no, la jusfilosofía de las postrimerías del siglo XX ha quedado marcada por este autor al que debemos, en definitiva, la aparición de una nueva especie de jurista: el homo dworkiniensis; como debemos a José María Sauca una oportuna taxonomía de sus variedades básicas, sobre las cuales a buen seguro teorizarán improvisados etnógrafos y antropólogos de la materia: dworkinistas, dworkinianos, dworkinólogos, dworkinautas y finalmente los anti-Dworkin (p. 15). Por lo que se refiere, en fin, a su tempo o su timing, el libro ha resultado ser de lo más vivace, en el sentido de que se anticipa incluso a los homenajes en preparación entre los anglófonos, tal y como se complace en subrayar el propio editor en sus palabras de presentación (p. 13).

Antes de entrar en más detalles, debo manifestar mi convicción de que la lectura de este volumen va a procurar a cualquier filósofo del Derecho una reflexión profunda y estimulante. Pero una vez aclarado esto y siquiera sea por no resultar demasiado complaciente, debo advertir de que la obsequiosa prontitud del homenaje admite al menos dos interpretaciones y de signo contrario. Por una parte, nuestro apresuramiento habla de la propia vitalidad de la jusfilosofía en lengua española, una jusfilosofía muy activa y atenta como pocas a lo que suceda fuera de su propia cultura jurídica. Por otra parte, estas prisas podrían interpretarse también como una manifestación más de servilismo hacia la filosofía jurídica dominante en lengua inglesa, lo cual resulta precisamente más de lamentar cuando reparamos en el brillo de una jusfilosofía hispanófona que no siempre ha gozado fuera de sus confines geolingüísticos de la atención que quizá mereciera. A veces se diría incluso que en el debate internacional tan sólo se repara en los jusfilósofos hispanófonos en la medida en que seamos solícitos traductores y fieles transmisores de las ideas de otros siguiendo una prelación que a menudo beneficia curiosamente al menos erudito y que guarda un parecido inquietante con una cadena trófica o un sistema de castas. Tradicionalmente, los anglófonos sólo han estudiado y citado a sus nativos, singularmente a los de Oxbridge y asimilados. Los germanófonos a esos anglófonos y a sí mismos; los italianos a anglófonos y germanófonos y a sí mismos; los hispanófonos - ya digo - se han consolado entre ellos mientras discuten sobre los anteriores; los lusófonos conocen y estudian bien a todos los previos y así se propaga esta prelación por ex-colonias y periferias. Caso aparte quizá sea el de los 
francófonos que se diría han decidido refugiarse en su jardín a la espera de recobrar la grandeur en el café jusfilosófico internacional.

Dejo a la consideración del lector concluir si esto no sea sino una manifestación gremial de un fenómeno racista más amplio al que Boaventura de Sousa Santos se refiere como "fascismo social" (Sousa Santos, 2005: 353 ss). En cualquier caso, si bien soy consciente de que, por razones puramente conceptuales, ningún libro de esta naturaleza se escribe para ser leído por el homenajeado y que lamentablemente Dworkin jamás podrá leer ya El legado de Dworkin; lo que estas reflexiones apenas compartidas me hacen sospechar es que, con toda probabilidad, Dworkin jamás lo habría leído de seguir todavía vivo y ello no deja de resultarme desasosegante.

\section{Una gloria sin paz}

Ciertamente no es este tipo de generalizaciones (quizá de mala nota en un académico riguroso) lo que nos convoca aquí; pero esta interpretación suspicaz, por la que habla la cautela frente al mainstream, pero también quizá cierto resentimiento periférico, nos interesa aquí y ahora porque la teoría de Dworkin no sólo presenta tesis controvertidas. En franco contraste con el tratamiento que reciben otros jusfilósofos célebres, la mera toma en consideración de su obra - su toma en serio - ha sido fuertemente contestada por muchos con insistencia y dado que Dworkin es autor que ha acompañado a menudo las reflexiones de quienes nos dedicamos a la filosofía jurídica, resulta inevitable echar la vista atrás en la propia biografía en busca de alguna experiencia dworkiniana expresiva de esta fama vacilante. Por azares de la vida tuve la oportunidad de asistir el año 1998 a una clase de grado de Dworkin en un aula de la Bodleian Law Library de Oxford que se encuentra en Saint Cross y debo confesar que para mí fue un momento especial. Doce años atrás, hacia 1986, había leído en el primer curso de la Licenciatura Los Derechos en serio por indicación de un brillante profesor de filosofía del Derecho de la Universidad de Barcelona, Albert Calsamiglia ${ }^{1}$. Aquella clase de grado de Dworkin me confirmó lo que muchos me habían anticipado: como docente resultaba seductor. Su lenguaje claro y directo en el aula contrastaba con su barroquismo por escrito y su constante remisión a las artes plásticas para establecer analogías con el Derecho me pareció reveladora de toda su filosofía. Por aquella época yo acababa de publicar en el Centro de Estudios Políticos y Constitucionales mi tesis doctoral bajo el título Principios y positivismo jurídico (A. García Figueroa, 1998) y en ella había sido muy crítico con la posición de Dworkin, siguiendo así la estela del pensamiento analítico hispano-italo-argentino dominante por entonces en nuestro país. De hecho, mientras escuchaba su lecture no pude evitar pensar algo así como "Dworkin es cautivador, pero creo que el profesor tal se levantaría ahora mismo para gritar con acento italiano: 'Bullshit!'”.

En efecto, uno puede declararse juspositivista o no -esto resulta cada vez más secundario y aun enigmático- pero a nadie se le pasaría por la imaginación poner en duda el genio y el rigor de Kelsen, por ejemplo. Y sin embargo, esta constatación nunca ha regido en el caso de Dworkin. Ciertamente, en El legado, algunos trabajos del volumen confrontan a Dworkin con otros pensadores como Berlin -es el caso de Óscar Pérez de la Fuente, pp. 503 ss-; Waldron -en el trabajo de Ricardo Cueva, pp. 459 ss- o el propio Kelsen, a cuyo contraste Alberto del Real examina su coincidencia (oppositorum) en materia de completitud del Derecho (pp. 483 ss)-, pero es claro que la gloria de Dworkin, a diferencia de la Kelsen, no es unánime ni entimemática. No todo el mundo da por descontada la seriedad del

\footnotetext{
${ }^{1} \mathrm{Y}$ de quien todos recordamos su ensayo introductorio precisamente a R. Dworkin (1977: 7-29).
} 
imperio forjado por el erizo de Massachussets. La alternativa se vuelve entonces extrema: ¿Es Dworkin un bluff de mainstream para consumo de papanatas (vid. Haba, 2011) o un académico serio y valioso llamado a persistir en nuestra memoria por mucho tiempo? En el propio volumen que da pie a estas reflexiones conviven afirmaciones implícita o explícitamente laudatorias con otras abiertamente despectivas. Hacia estas segundas formas extremas de dwokescepticismo me permito manifestar una actitud de escepticismo con matices. Seguramente Dworkin tenga razón en muchas de sus tesis, pero al mismo tiempo su obra bien podría yacer polvorienta e ignorada en los anaqueles de una de nuestras bibliotecas universitarias, de haber nacido Dworkin digamos que en Navalcarnero. Pero veamos cómo se manifiesta el contraste sobre la consideración de nuestro autor entre algunos participantes en El legado.

Isabel Lifante afirma que es "imposible hablar de interpretación en el Derecho sin hacer mención de la obra de Dworkin" (p. 161) y en parecidos términos Marisa Iglesias escribe que "la concepción interpretativa del Derecho de Ronald Dworkin es una de las aportaciones más ricas y complejas a la teoría jurídica contemporánea" (p. 233). Y si Iglesias no oculta su admiración por "el talento y maestría de Dworkin" (p. 253); María José Añón destaca su "magistral agudeza" (p. 364) y Francisco Laporta se maravilla de "su capacidad inmensa y brillante para argumentar y ergotizar" (p. 37). Si la teoría del Derecho de Dworkin constituye un "referente indiscutible del antipositivismo del siglo XX", como apunta Mariano Melero de la Torre (p. 281), su filosofía política liberal "ha supuesto un desafío intelectual para otras corrientes del mundo académico que creían no haber encontrado rivales de su talla", nos dice Ricardo Cueva Fernández (p. 468). Y si Dworkin brilló en el mundo de las ideas, lo hizo también en la práctica -asegura Ángel Pelayo- como cualquier otro miembro del "grupo de los grandes intelectuales comprometidos social y políticamente que alumbrara la Ilustración" (p. 334). Nada menos. A nadie ha de sorprender el tono elegíaco y solemne para el que tan propicias resultan estas ocasiones; sin embargo, en el libro pronto se cierne amenazante la sombra de un arquetipo jusfilosófico: el anti-Dworkin estándar, si puedo llamarlo así. Atienza, quien elogia con contención la aportación de Dworkin a la teoría del Derecho, reconoce que "el estilo literario de Dworkin no es un prodigio de claridad y (...) que sus tesis teóricas podrían expresarse con mayor claridad (...)" (p. 75), pero a renglón seguido se desmarca de ese anti-Dworkin estándar en cuya boca pone la siguiente declaración de rancio dworkescepticismo:

Dworkin ha puesto de moda una manera de hacer filosofía del Derecho que se caracteriza por el uso de un lenguaje y la difusión de un pensamiento oscuros que, en lugar de ir más allá del positivismo jurídico de corte analítico (más allá de Hart), supone más bien una regresión a épocas pretéritas, a las oscuridades del iusnaturalismo pre-benthamita" (p.75).

Y precisamente esa sombra siniestra se hace carne (o papel) en ese mismo volumen cuando recorremos las páginas del artículo de Juan Antonio García Amado, quien nos anticipa en los primeros compases de su artículo un ataque que a continuación desplegará sin contemplaciones. Estas son sus palabras:

Considero que muchos de los razonamientos de Dworkin forman un catálogo de peticiones de principio y un alarde de quimeras verbales, amén de que casi nunca entiende o toma en serio las doctrinas que dice rebatir, sean las que sean, sino que las deforma a conciencia para ponerlas al nivel de los galimatías conceptuales que le son propios. No me corresponde a mí averiguar los secretos del éxito de un autor tan incongruente, escasamente erudito, no particularmente laborioso ni dado a la lectura de obras ajenas y cuyos escritos de teoría del Derecho son, en alta proporción, sencillamente incomprensibles (p. 128). 
A lo largo de su contribución al Legado (pp. 127 ss), García Amado tratará de disuadirnos de tomar en serio Los derechos en serio y singularmente uno de sus principales argumentos: la distinción entre reglas y principios y su presunta virtualidad antipositivista. García Amado orilla explícitamente (p. 127) el resto de la obra de Dworkin, con lo que implícitamente viene a sugerir que Taking Rights Seriously es la parte más atendible de sus escritos. A mí me parece que, en efecto, el hecho de que Dworkin planteara su obra Los derechos en serio como un "ataque general al positivismo jurídico" que apuntaba al positivismo hartiano (vid. Hart, 1994) sirvió para que algo del espíritu analítico hartiano impregnara a Dworkin con el estilo argumentativo más claro de su adversario. Quizá por ello haya hecho bien García Amado en concentrarse en la pars destruens de la obra de Dworkin -la construens es fatalmente hermenéutica- y dentro de aquélla en el tratamiento dworkiniano del célebre caso Elmer (Cano, Zamora y Guzmán, 2007).

Leyendo a García Amado da a veces la sensación de que su irritación con Dworkin fue creciendo por momentos a medida que escribía. Si hacia la página 145 dice contenido que "el rigor analítico no es el punto fuerte de la obra de este autor [Dworkin]" y a la siguiente que "seguimos sumando incongruencias" (p. 146), luego ya comienza a quejarse de "que sus distinciones hacen aguas y tienen más agujeros que un colador" (ibid.). A continuación se toma un descanso quizá por atajar a quien se viera tentado de tildarlo de prejuicioso, y en él García Amado se duele de que la argumentación de Dworkin "no es nada fácil de entender (...) ni con buena voluntad" (p. 148) y de que, por más que lo intentemos, "seguimos sin enterarnos de cómo distinguir una regla de un principio" (ibid.). Su monumental cabreo -es necesario algo de strong language para transmitir adecuadamente el tono- le lleva a concluir su examen de Dworkin con ironía: "Impresionante. A cosas así fue a parar la teoría del Derecho del último cuarto de siglo XX. Y por ahí sigue" (p. 153). No sin cierta amargura positivista, García Amado concluye así su diagnóstico, entre sarcástico y despechado:

La teoría dworkiniana de la única respuesta correcta (y de los principios que la alimentan) es la teoría de que la única respuesta correcta existe porque los jueces creen que existe, aunque no puedan saber cuál es esa respuesta para cada caso y solo les quede pensar que cuanto más convencidos estén, más cerca andarán de ella. En la búsqueda de la verdad, también en el Derecho, lo importante es participar. No como los positivistas, que no creen en nada y no tienen ni principios ( $p .157)$.

Por más que se encuentre en franca minoría, García Amado no es el único autor del panorama jusfilosófico que piensa de este modo, ni mucho menos; así que los fuertes desacuerdos sobre el gran teórico de los desacuerdos deberían llevarnos a la reflexión. ¿Cómo resolver entonces estas discrepancias interpretativas sobre el valor real de la teoría interpretativa de Dworkin? ¿Es Dworkin el erizo de una sola pero sólida arma o bien un zorro oportunista de múltiples ardides que se entrega al sofisma? ¿Quizá nos encontramos ante un "zorrizo", como conjetura Pablo de Lora (p. 443, nota 15)? Llegados a este punto, no es fácil saber quién tendrá la razón y en realidad buena parte del cometido del libro consiste en darnos pistas para que cada cual resuelva el enigma por su cuenta. De lo que sí estoy seguro es de cómo no debe resolverse y es acudiendo a las estadísticas. En primera instancia, el editor (p. 14) parece ceder a la tentación de consultar de soslayo los índices de impacto, comparando los datos sobre citas que al respecto proporciona Shapiro. El partido quedaría así: Posner 7981 - Dworkin 4488. Creo que ninguna persona cultivada -y el profesor Sauca lo es distintivamente- debería ceder a la tentación de entregarse a estas disquisiciones estadísticas que entre nosotros ha puesto de moda con nauseabundo éxito una institución tan nefasta para el prestigio y el futuro de nuestra 
Universidad como la ANECA. Una buena jusfilosofía bien puede ser y, en su caso, debe serlo -imire usted por dónde!- un "triunfo frente a la mayoría"².

\section{3. ¿A qué se debe el éxito de Dworkin?}

Naturalmente, en su contribución acerca del liberalismo y la identidad en Dworkin, José María Sauca refina sensiblemente esos criterios de valoración sobre Dworkin y nos ofrece un análisis breve pero certero de las causas y las razones del auge del imperio dworkiniano (pp. $311 \mathrm{~s}$ ). Para Sauca las causas contextuales que explican el éxito de Dworkin obedecen a la hegemonía de la cultura estadounidense en tres planos distintos pero conexos: el jurídico, el político y el institucional. Ciertamente, la jurisprudence estadounidense, basada en el caso y de la cual Dworkin es paradigma, se ha erigido en algo así como la cultura jurídica franca de nuestro tiempo. Además - viene a añadir Sauca- políticamente se han impuesto los modelos de la reflexión usamericana justo cuando no conseguían levantar cabeza los de la socialdemocracia europea continental y -por si todo ello fuera poco- a la caída de los regímenes soviéticos y de las dictaduras militares le habían sobrevenido sistemas constitucionales y de control de constitucionalidad armónicos con buena parte de la reflexión constitucional estadounidense. Como bien dice Sauca, en aquel contexto jurídico anglófilo y yankófilo, Dworkin "tenía muchas papeletas" (p. 312).

En cuanto a las razones sustantivas del éxito del "liberalismo jurídico" ( $p$. 313) de Dworkin (i.e. las razones que pretenden justificarlo por su validez y no sólo explicar su difusión imperialista), Sauca indica la reintroducción de la "perspectiva valorativa en el seno del Derecho", "la concepción interpretativa o argumentativa del Derecho" o la "reactualización del objetivismo, constructivismo o simplemente cognitivismo moral" (p. 312). El análisis pormenorizado del papel de los derechos culturales en la teoría liberal e individualista de Dworkin conduce a Sauca a un diagnóstico de orden general: Lo que explica el éxito de la teoría de Dworkin, i.e. su fuerte arraigo contextual, es también la causa de sus deficiencias (p. 330).

En efecto, creo que merece una reflexión aparte el hecho de que haya gozado de tal aceptación entre nosotros un autor que une dos características que vuelve inexplicable ese éxito: imperialismo y particularismo. Es, en efecto, uno de esos "filósofos del verbi gratia" -en la feliz expresión de Margalit que recoge Sauca (p. 312) - y esto significa que tiende al particularismo teórico; es decir, reflexiona a partir del caso concreto y tiende a restringir a él el alcance de sus conclusiones. No por casualidad y consecuente con ello, Dworkin ha restringido más de una vez el alcance de su teoría a los confines de los Estados Unidos y también a Gran Bretaña, sin apenas prestar atención a lo que suceda fuera de su propia cultura jurídica. En tales circunstancias, es saludable que la recepción de su teoría sea cautelosa.

Por otra parte, el hecho de que el éxito de Dworkin entre nosotros se deba a la "reintroducción" de la interpretación, los valores o el objetivismo moral en la filosofía jurídica (p. 312) -lo que cabría denominar su "jusnaturalismo hermenéutico"- creo resulta hasta cierto punto cómico no bien lo pensemos con calma: resulta que la tradición anglófona se ha apropiado de la tradición analítica, dejando la hermenéutica para lo que ellos llaman "el continente" -y ya se sabe lo que sucede con el que parte y reparte-. Resulta que se trata de una apropiación más bien indebida si atendemos al buen criterio de algunos anglófonos con mala conciencia que nos recuerdan que la analítica es más bien una tradición austro-

\footnotetext{
${ }^{2}$ Dworkin (1984: 37) se refiere a los derechos como triunfos políticos oponibles a la mayoría en una de sus más célebres imágenes.
} 
angloamericana (vid. M. Dummett, 1993: 1s). Y resulta, en fin, que cuando la tradición hermenéutica alza la voz con cierto éxito también lo hace desde la cultura jurídica anglófona (i.e. analítica), y entonces nos viene con Ronald Dworkin, quien para colmo no suele hacer mucha justicia a sus fuentes bibliográficas.

En efecto, como ha sugerido irónicamente Jesús Vega, en este aspecto Dworkin no recuerda a un erizo, sino más bien a "un zorro que se dedica a borrar con la cola las huellas de los autores a los que sigue, para que no quede el menor rastro" (p. 79, nota 5)-. De ahí la desazón que expresa Andrés Ollero por el desapego de Dworkin con la tradición jusnaturalista y su oportuna indicación de las citas de Gadamer en Dworkin (p. 119); de ahí la oportuna referencia a precedentes ignorados o arrollados al paso de Dworkin tales como Grundsatz und Norm de Josef Esser (García Amado, p. 128) o de Roscoe Pound y Fuller (Atienza, p. 79); de ahí la procedencia del paralelismo que nos propone, en fin, García Bermejo con la teoría de Stammler (pp. 182 ss). Se trata de llamadas de atención que nos exigen prudencia ante los descubrimientos recurrentes del Mediterráneo desde tierras más frías y deberían llevarnos, en fin, a contenernos en la exhibición de nuestras pasiones, que algún tercero quizá pudiera interpretar como aspavientos jusfilosóficos de cheerleader.

Me parece que junto al de Sauca, hay al menos otros tres trabajos que sugieren la necesidad de cierta contención a la hora no ya de jalear a Dworkin, sino sobre todo -y esto es lo más importante- de adoptar sus recetas. Se trata de los trabajos de María José Añón, Isabel Turégano y Ángel Pelayo. Añón desarrolla un minucioso trabajo de ordenación de los argumentos a favor de la affirmative action en la jurisprudencia estadounidense y en Dworkin en relación con el acceso a la Universidad de la minoría negra. La naturaleza estructural de la discriminación (pp. 382; 385) y la asunción del valor de la diversidad (p. 384) son argumentos esenciales del debate, a cuyo detallado análisis antecede la advertencia insistente y reiterada por Añón de que "(I)a toma de posición del autor sobre la acción afirmativa no puede desligarse del contexto social, jurídico y político en el que escribe, ni tampoco del momento concreto..." (p. 363).

Con todo, quizá resulte más incisivo en este aspecto el trabajo de Isabel Turégano que se ocupa de la filosofía del Derecho internacional de Dworkin, algo que, significativamente, "no fue una preocupación central" en su teoría (p. 413). Turégano lamenta que "el potencial radical" de la idea dworkiniana de dignidad ( $p$. 428) y el cacareado igualitarismo dworkiniano que algunos autores han querido explotar para el desarrollo de una justicia distributiva global no consigue ir más allá de las fronteras de los Estados. La conclusión de Turégano, no exenta de cierta frustración, es que "no es posible la extensión global del modelo de igualdad de Dworkin" (p. 432) porque el modelo dworkiniano está comprometido con una "comunidad de principio" que conduce más bien a una estructuración en "esferas de justicia" (p. 433) y no es de extrañar que estas esferas comunitaristas alejen a Dworkin de su propia "tesis de la unidad de valor" (p. 433).

Finalmente, Ángel Pelayo recorre las ideas de Dworkin sobre el aborto y la eutanasia subrayando con insistencia el carácter fuertemente situado de su discurso. "El Dworkin estratega" (p. 349) redefine y defiende "lo sagrado" en el contexto americano para "presentar una posición menos agresiva" (p. 341) o para "no ser sospechoso de falta de patriotismo" (p. 345). En ambos casos, los planteamientos de Dworkin cobran su sentido en el debate donde se origina y pensando en los interlocutores que allí pueda tener. 
Sin miedos a las particularidades del American way of life (and death) en Dworkin, diríase en cambio la contribución de Pablo de Lora sobre la justicia distributiva en materia sanitaria que él aplica eficazmente al examen de un caso en España, el caso Losada, donde se planteaba si el Servicio Gallego de Salud debía sufragar los más de 360.000 euros anuales que costaba el tratamiento de una enfermedad rara. El principio fundamental de Dworkin consiste, dada la escasez de recursos, en que cada cual reciba como máximo aquello que la propia persona habría estado dispuesta a asegurar con ciertas correcciones ideales de las desigualdades (p. 439). Tras examinar las ventajas e inconvenientes de este experimento mental, De Lora presenta serias objeciones a esta visión fuertemente liberal e individualista, introduce correcciones de orden compasivo o humanitario y pone en cuestión la validez normativa del experimento mental que Dworkin propone (pp. $454 \mathrm{~s}$ ). Un par de dudas nos asaltan entonces: ¿Hasta qué punto no serán los de De Lora argumentos arraigados a nuestra forma de vida, digamos, continental? ¿No podría algún defensor de la ética protestante detectar maliciosamente en las objeciones de Pablo de Lora un tributo a una forma de vida impregnada de catolicismo?

\section{4. ¿Cómo aproximarse al legado de Dworkin?}

Para este comentarista no es fácil dar cuenta de un libro que en un estado preinterpretativo agrupa escritos muy diversos a pesar de referirse a un mismo autor, pero es de agradecer que se hayan estructurado persuasivamente -como una especie de tributo a la dimension of fit dworkiniana- en siete capítulos donde se abordan siete temáticas bien trabadas de lo más general y abstracto a lo más particular y concreto. Es verdad que la casualidad ha querido que las contribuciones de los catedráticos más antiguos se agolpen al principio dejando a la práctica totalidad del resto del escalafón para el final. Y no será por revertir este azar de querencias gerontocráticas por lo que voy a saltarme -ya he comenzado a hacerloese orden lineal a fin de guiar de un modo alternativo al lector. Después de todo, la búsqueda de la coherencia de los materiales preinterpretativos de El legado de Dworkin puede hacerse por múltiples vías interpretativas.

Por eso, mi consejo al lector no iniciado sería comenzar la lectura con la presentación clara y directa que nos proporcionan las primeras páginas del artículo de Pablo Raúl Bonorino (pp. 255-261). Quien se quede para concluir este primer trabajo, entonces verá cómo, tras ese ejercicio de fitness interpretativo en que el profesor de Vigo reconstruye las tesis más influyentes de Dworkin de manera económica, eficaz y clara, Bonorino se lanza a interpretarlas a su mejor luz. En esta fase postinterpretativa Bonorino trata de desarrollar lo que para él es la visión más sólida -soundest, nos diría el propio Dworkin- del legado dworkiniano. En este punto, la aportación de Bonorino resulta particularmente creativa y estimulante, cuando aplica los recientes desarrollos de Atocha Aliseda sobre la abducción al razonamiento jurídico dworkiniano. El razonamiento abductivo hallaría su sitio así en la interpretación constructiva de Law's Empire, aunque a mí me parece que esta aportación podría ser más prometedora puesta en relación con el debate sobre la derrotabilidad de las normas al que hemos llegado hoy en día a partir de la lejana discusión sobre reglas y principios que alumbró Dworkin en Taking Rights Seriously. Como en el caso de la derrotabilidad ante los casos difíciles, el razonamiento abductivo sirve en la propuesta de Bonorino para dar adecuada cobertura a dos tipos de casos difíciles: las novedades y las anomalías (pp. $266 \mathrm{~s}$ ). Dejando al margen el encaje de este planteamiento en una u otra parte de la teoría de Dworkin, lo cierto es que Bonorino va mucho más allá de Dworkin. Siendo conscientes de ello, creo que un libro como el que nos ocupa se justifica precisamente por esta 
ampliación de los horizontes de una teoría y no por sus exégesis más o menos eruditas.

Otra vía de acceso privilegiado al estudio de Dworkin nos la ofrece Isabel Lifante. Su contribución no sólo afronta el estudio de la interpretación en Dworkin con extraordinaria claridad; además destila una suerte de rara ecuanimidad, de justa distancia frente al pensamiento dworkiniano, que presenta un valor especial cuando de este autor que levanta pasiones se trata. Lifante examina un tema central y de ramificaciones arborescentes en lo que ella denomina "el giro interpretativo" de Dworkin (pp. $161 \mathrm{~s}$ ). El texto de Lifante demuestra eficazmente cómo la interpretación en Dworkin no sólo es lo que hacemos con el Derecho. El Derecho es en sí mismo una práctica interpretativa y para acabar de complicar las cosas, "la interpretación es (...) interpretativa" (p. 164), en palabras de Dworkin sobre las que Lifante llama la atención para poner de manifiesto la insistente difuminación de los niveles de lenguaje en Dworkin (p. 170). El rechazo dworkiniano del "arquimedismo", de la perspectiva "hacia abajo, desde fuera y desde arriba" (ibid.) conduce finalmente a la invariable vinculación de la interpretación a la valoración moral, lo cual no sólo tiene consecuencias para la interpretación del Derecho, sino que también funda el concepto antipositivista de Derecho de Dworkin.

Precisamente, el enfoque clásico de Gema Marcilla tiene la virtud de inscribir el legado de Dworkin en el marco amplio del debate con el positivismo jurídico hartiano del que en primera instancia el autor norteamericano sale victorioso para imponerse además a dos posibles alternativas: el pospositivismo y el realismo jurídico (p. 216). Sin embargo, se trata de una victoria provisional. Marcilla recupera eficazmente las estrategias defensivas del positivismo: el analítico de Raz, el incorporacionismo bajo sus diversas denominaciones y la "tesis de la excepcionalidad de la interpretación" (p. 219) en donde se situarían los planteamientos de Juan Carlos Bayón en nuestro país. Una vez examinadas, se reafirma en el triunfo de las "tesis iusmoralistas" (p. 221); si bien su trabajo es rico en matices que le llevan a replantear sus dudas sobre el alcance real del antipositivismo dworkiniano. No sólo porque no es claro si "destrona necesariamente la tesis de la separación conceptual entre Derecho y moral" (p. 224), sino además porque la "teoría de la verdad moral de Dworkin resulta ambigua" (p. 225). Si el trabajo de Lifante mantiene una distancia medida y constante con el pensamiento de Dworkin, el de Marcilla se aproxima y aleja de él a lo largo de sus páginas con el objetivo de que sea el lector el que conforme su punto de vista.

Pero la distancia con Dworkin no sólo la marca la adhesión o no a sus tesis. El -digamos- perspectivismo que fomenta su análisis nace también de su personalísima forma de afrontar los problemas. A medida que uno avanza por el libro, se multiplican, incluso a mayor ritmo que los elogios, las expresiones de vacilación a la hora de interpretar a Dworkin. Con todo, los participantes en el volumen hacen un gran esfuerzo por clarificar las ideas de Dworkin y en especial por mostrarlas a su mejor luz; y a menudo adaptan a Dworkin a sus propias necesidades, por así decir. Si de Kant se llegó a decir que "cada cual lee su Kant", quizá con más razón pueda decirse aquí que cada cual interpreta su Dworkin. En el caso de Mariano Melero de la Torre, esta adaptación pasa por una fullerización de sus planteamientos. Con ese fin, Melero revisa las ideas de Dworkin a la luz de autores como Waldron y Postema para conformar su propia posición crítica. Melero cree, en síntesis, que "la identificación del Imperio de la Ley con el Imperio de la justicia" (p. 301) en que incurre Dworkin le conduce tanto a la desvirtuación del ideal de la justicia como a la legitimación de sistemas jurídicos inaceptables (ibid.) y sostiene que la solución pasa por vincular la dimensión justificativa de la legalidad algo valioso en Dworkin según Melero (p. 281)- no a "una moralidad sustantiva 
externa al Derecho" (p. 302), sino, à la Fuller, a "principios que se siguen del modus operandi del Derecho" (ibid.).

Sin embargo, creo que al lector algo más comprometido con la teoría de Dworkin le agradará comenzar con la reflexión de Marisa Iglesias. La autora exhibe una deslumbrante comunión con el pensamiento dworkiniano que va mucho más allá de su erudición en la materia, demostrada en trabajos anteriores ${ }^{3}$. Iglesias no sólo maneja con tremenda soltura el magmático -que no sistemático- conjunto de tesis y conceptos dworkinianos, sino que además nos sugiere una reelaboración de esas tesis para proponer un nuevo concepto: "la igualdad axiológica ante la ley" (p. 233). Iglesias recalifica dworkinianamente los términos de la discusión sobre la función judicial, creando nuevos conceptos que a veces -se nos antoja- podrían tener nombres más sencillos, en especial si atendemos al parecido que algunos planteamientos guardan con los del par alemán de Dworkin, Robert Alexy. En efecto, Alexy aparece en el elenco de referencias bibliográficas del artículo, pero no en el cuerpo del texto -quizá también por influencia del maestro Dworkin, tan parco y opaco a la hora de referir sus fuentes-. Pues bien, no es por hacer ascos a los neologismos, pero, cabe preguntarse si no sería más sencillo, por ejemplo, distinguir con Alexy las teorías internas y externas de los límites de los principios jusfundamentales que hablar de su "acomodación interna" y "acomodación externa" como "dos posibles formas de armonización axiológica" (pp. 240 s) en Dworkin.

\section{Dworkin, ¿Un insospechado icono constitucional para gays y lesbianas?}

Por lo demás, a la hora de asesorarse Iglesias no duda en dar un descanso al atareado juez Hércules e insuflar vida a una juez ordinaria de nombre Temis, de sabiduría pareja a la del famoso Hércules dworkiniano (p. 236). En un plano simbólico, la sustitución de Hércules por esta divinidad jurisdicente podría parecer una mera corrección de orden feminista contra el patriarcado olímpico; pero también cabría interpretar el recurso a Temis como el reconocimiento de que todo juez ideal tiende a convertirse en un alter ego de su creador y por tanto no deberíamos confiar demasiado en la imparcialidad de sus decisiones -en este sentido, García Amado, sospecha irónico "que Hércules es en realidad Ronald Dworkin, pero no pued[e] probarlo" (p. 155)-. Sea como fuere, el caso es que Iglesias consulta a Temis sobre una cuestión jurídica que, por lo que veremos, el azar ha querido hacer presente felizmente en más de un lugar del libro. Me refiero a la constitucionalidad del matrimonio homosexual en España antes de la Sentencia del Tribunal Constitucional (STC 198/2012 de 6 de noviembre) que declaró su constitucionalidad. ¿Cómo habría actuado Temis desde su juzgado? Pues bien, al parecer Temis se las vería y se las desearía para resolver con integridad y por eso se mostraría tremendamente vacilante en su decisión (pp. 242-245), así que me parece -esta ya es una propuesta de mi responsabilidad- que no estaría de más convocar a otros magistrados de carne y hueso: los de nuestro Tribunal Constitucional. Veámoslo.

Ante todo conviene decir que por su farragosa argumentación, la Sentencia del Tribunal Constitucional necesitaría, a trechos, la ayuda de varios jueces del Olimpo juntos para resultar no ya persuasiva sino comprensible, pero a cambio disponemos de un voto particular bien escrito precisamente por uno de los colaboradores de El Legado de Dworkin, el magistrado Andrés Ollero. Su voto particular resulta particularmente valioso en este contexto porque en su numeral cuarto Ollero involucra en la discusión constitucional a un "prestigiado autor, estudioso de la jurisprudencia constitucional norteamericana" que no es otro -salvo que yo me equivoque gravemente- que el propio Ronald Dworkin. Y Ollero lo hace

\footnotetext{
${ }^{3}$ Su influjo ya se aprecia en Iglesias Vila (1999).
} 
porque en la constitucionalidad del matrimonio homosexual se enfrentaban al fin y al cabo dos posiciones relevantes aquí: una tendencialmente originalista (que el propio Ollero sostenía y que no estaba en contra del reconocimiento del matrimonio homosexual, sino que exigía una reforma del art. 32 Const. que le diera su acomodo institucional adecuado) y por otra parte, se hallaba la posición dominante del alto Tribunal que aparentemente concibió el matrimonio à la Dworkin como un concepto que admitía sucesivas concepciones en su seno ${ }^{4}$. Desde esta última perspectiva, el concepto de matrimonio entre hombre y mujer del art. 32 admitía entonces la concepción del matrimonio homosexual. Hubo acuerdo en que el TC no considera la posibilidad de que "hombre y mujer" pueda aludir en el art. 32 Const. a que cada cual -cada hombre y cada mujer- pueda a su vez contraer matrimonio con un hombre o con una mujer a voluntad, así que la cuestión quedaba planteada así: reforma constitucional sí o no -i.e. no, bajo la cobertura de que el matrimonio homosexual es una concepción interpretativamente plausible del concepto de matrimonio del artículo 32 Const.-. Creo que la claridad argumentativa del voto particular de Ollero reflejaba una mayor plausibilidad y si trajéramos a Temis -no a Hércules- a la discusión, ella pensaría que en términos de proporcionalidad, la colisión del valor de la igualdad que se pretende garantizar para parejas homosexuales con el principio formal de la seguridad jurídica debería resolverse a favor de este segundo en razón del segundo principio de proporcionalidad, el de necesidad. En mi opinión, al objeto de proteger la igualdad de las parejas homosexuales existía un medio menos lesivo que someter a un sobreesfuerzo interpretativo al art. 32 Const. y ese medio era la reforma constitucional que el voto particular de Ollero sugería. La propia Temis-Iglesias argumenta de modo parecido cuando desde su juzgado sostiene que "la intervención del juez ordinario se torna menos necesaria" (p. 244, cursivas mías) en la medida en que "cabe confiar (...) en que la legislación, como ha acabado sucediendo en España, terminará estableciendo una equiparación plena [entre matrimonios heterosexuales y homosexuales]" (ibid.). Este cálculo de probabilidades es típico de la ponderación. Así que el caso del matrimonio homosexual guiaría nuestra lectura no sólo por la magistrada Iglesias-Temis, sino también por la crítica del magistrado-jusfilósofo Andrés Ollero a Dworkin y aún, por cierto, a la contribución de José Juan Moreso.

\section{La persuasiva doctrina Julia Roberts}

En efecto, también José Juan Moreso se refiere a la Sentencia del Tribunal Constitucional sobre el matrimonio homosexual (p. 94) para ilustrar cómo los desacuerdos sobre lo que el Derecho es, son desacuerdos interpretativos y morales. En su trabajo Moreso expresa un acuerdo general con el antipositivismo de Ronald Dworkin y condensa la teoría del Derecho de Dworkin en torno a dos tesis centrales: (i) El Derecho es la institucionalización de la moralidad pública y (ii) Hay desacuerdos teóricos generalizados acerca de lo que el Derecho dice (p. 92). Como sabemos, ambas tesis se entrelazan en Dworkin porque esos desacuerdos se resuelven mediante una argumentación moral tal y como se aprecia en lo que Moreso ha denominado la "doctrina Julia Roberts" (pp. 96 ss). No es la primera vez que Moreso reviste su argumento con el persuasivo glamour de la novia de América -que así cualquiera, la verdad-. Brevemente, en la película El informe Pelícano la

\footnotetext{
${ }^{4}$ Como es sabido, el debate entre la posición originalista y la de Dworkin alcanzó notoriedad en los Estados Unidos en la era Reagan cuando el originalista ultraconservador Robert Bork fue propuesto como magistrado de la Corte Suprema. En nuestro país, un libro de Miguel Beltrán, Originalismo e intepretación. Dworkin vs. Bork. Una polémica constitucional, da buena cuenta del debate BorkDworkin en los medios de comunicación y el de Pablo de Lora (La interpretación originalista de la Constitución. Una aproximación desde la filosofía del derecho) analiza el originalismo como teoría de la interpretación constitucional en un plano jusfilosófico.

${ }^{5}$ Vid. e.g. Moreso, Prieto y Ferrer (2010).
} 
estudiante de Derecho Darby Shaw (la Roberts) interpela a su profesor de Derecho constitucional diciendo que la Corte Suprema se equivoca en un fallo. Que sea posible un desacuerdo fundado acerca de la validez de un fallo constitucional constituye un serio problema para el positivismo jurídico, para el cual tiene validez (formal) lo que diga la Corte Suprema, mas no lo que pueda decir miss Shaw por muy (sustantivamente) válido que nos pueda parecer su juicio.

Pues bien, Moreso está de acuerdo con la doctrina Julia Roberts y por tanto con Dworkin, pero cree que hay tres excepciones que le mantienen aherrojado al positivismo jurídico à la Raz. En escritos anteriores Moreso había mantenido su pudor positivista gracias al ejemplo del Derecho romano arcaico y el célebre caso de las Instituciones de Gayo, en que el litigante pierde su viñedo por decir "viniae" y no "arbora" tal y como indicaba la intocable fórmula correspondiente. Ese caso mostraba que era posible blindar el Derecho respecto de toda consideración moral. Sin embargo, el arcaísmo del ejemplo parece contraproducente en el sentido de que nos muestra precisamente cómo ya no es el Derecho en realidad. El ejemplo funcionaba, a su pesar, más bien como un contraejemplo. Pues bien, Moreso actualiza su planteamiento mediante el recurso a tres casos más intemporales a los que llama "los intocables" (p. 101), porque serían algo así como fuentes jurídicas inmunes a la argumentación moral, inmunes a la doctrina Julia Roberts. Quizá podríamos llamarlos también los "inderrotables" o "Los indestructibles" (para los que tenemos niños):

“(a) Las reglas sustantivas contenidas en las decisiones judiciales y administrativas individuales".

(b) Las reglas procesales que definen las instituciones jurídicas: el Parlamento, el Tribunal Supremo, el Tribunal Constitucional, por ejemplo.

(c) Las reglas procesales que establecen cuáles son las decisiones judiciales finales y definitivas, que definen la res iudicata" (ibid.).

Pues bien, no sé hasta qué punto sean tres auténticos intocables. Quizá cada uno de estos intocables esconda bajo los faldones de la gabardina su propio talón de Aquiles:

Ad (a): Las decisiones judiciales individuales -por ejemplo, una Sentenciano parecen muy relevantes a la hora de hablar de la naturaleza del Derecho. En la medida en que son individuales, no son Derecho, sino más bien la aplicación más o menos acertada del Derecho. Si lo que Moreso quiere decir es que no podemos atacar una decisión firme, entonces estamos hablando de otro intocable, el intocable (c). Vayamos pues a los otros dos intocables, de carácter procesal y no ya sustantivo que, a decir verdad, tampoco parecen del todo intocables:

Ad (b): Dejando a un lado que las reglas que definen las instituciones del Estado han dejado de ser intocables hace tiempo en nuestro país -pensemos en el caso que el Parlamento catalán hace al Tribunal Constitucional, por ejemplo-, Moreso establece un requisito importante para que el intocable (b) lo sea de verdad. Las reglas que definen las instituciones fundamentales de un Estado son intocables -dice Moreso (ibid.)- si están fijadas "de modo no controvertible"; pero aquí incurre en una petición de principio, pues lo que define la intangilidad es precisamente la incontrovertibilidad. Si lo que quiere decir Moreso es que las normas no controvertibles son no controvertibles, entonces simplemente afirma algo trivial; pero la realidad es que cualquier apertura a la interpretación es una apertura a la argumentación práctica en alguna medida y lo que parece verdaderamente dudoso es que existan normas no controvertibles. Esto es lo que habría que demostrar y 
creo que Moreso no lo hace aquí convincentemente. De hecho, no proporciona ejemplos concretos.

Ad (c): Las reglas sobre cosa juzgada son realmente muy importantes en cualquier Estado liberal y son una exigencia esencial de la seguridad jurídica, pero no creo que excluyan absolutamente su tangibilidad o derrotabilidad por razones morales. Es verdad que su exceptuación tendría lugar en muy pocas ocasiones, pero que sucediera excepcionalmente no nos autoriza a excluirlo de nuestros esquemas conceptuales. Después de todo, una disposición puede permanecer latente y no manifestarse jamás sin que a nadie se le ocurra por ello negar tal disposición. Por ejemplo, si meto algo de sal en una cámara acorazada herméticamente cerrada, a nadie se le ocurrirá decir que esa sal ya ha dejado de ser soluble en agua. Simplemente habremos cancelado la posibilidad de que esa disposición de la sal a disolverse en agua se manifieste. De vuelta al caso de la regulación de la cosa juzgada, imaginemos (sin mucha imaginación) que unos judíos fueron desposeídos de sus bienes inmuebles por una sentencia bajo el régimen nacionalsocialista. ¿De verdad no cabría en ciertas circunstancias revisar interpretativamente esa sentencia por muy poco controvertible que pareciera la regulación nacionalsocialista de la cosa juzgada? En suma y ya que en estas estamos, creo - por acallar a los alarmistas que consideran el neoconstitucionalismo una especie de apocalipsis jurídica (e.g. Laporta, 2007)- que Julia Roberts debe respetar en principio a los intocables de Kevin Costner, pero eso no significa que deba extremar el pudor hasta convertirse en una mojigata del positivismo soft.

\section{La filosofía moral del jusnaturalismo dworkiniano}

Como avanzaba más arriba, a Andrés Ollero le debemos el voto particular a la STC 198/2012 de 6 de noviembre, pero también un artículo del volumen en torno al concepto de moralidad política y Derecho natural en Dworkin. Si Iglesias es una intérprete quasi-auténtica de Ronald Dworkin y Moreso un dworkiniano con reparos, Ollero es algo así como el negativo de Ronald Dworkin, pues representa a un positivista convencido que además cree firmemente en el Derecho natural. Por eso se queja por igual del "vapuleo" sufrido por el positivismo jurídico clásico ( $p .105$ ) como de la "alergia a lo religioso" de Dworkin (p. 109). Para Ollero el "ateísmo religioso" (p. 116) de Dworkin tiende a fundar un "laicismo confesional" (pp. $111 \mathrm{ss.).}$ Particularmente en cuestiones bioéticas y con el pretexto de la "presunta neutralidad laicista" de su moralidad pública (p. 123), Dworkin no haría otra cosa, a juicio de Ollero, que rescatar el viejo Derecho natural para imponer con él una ideología individualista.

A este respecto, resulta de particular interés confrontar la posición de Ollero con la de Atienza, un autor mucho más cercano a las posiciones de Dworkin precisamente en las delicadas cuestiones bioéticas donde el disenso se manifiesta en consecuencias jurídico-políticas sensibles. Atienza reconstruye cuidadosamente la argumentación de Dworkin a partir del caso Cruzan, sobre eutanasia (pp. $82 \mathrm{ss),}$ para mostrar no sólo la posición de Dworkin al respecto, sino también la incidencia de una concepción positivista o no en la aplicación del Derecho. La vinculación del razonamiento jurídico al práctico general (pp. 87 ss) conduce a la integración en el razonamiento jurídico de una serie de argumentos morales en torno al carácter sagrado de la vida. Estas consideraciones nos conducen casi naturalmente a las dos primeras contribuciones del volumen sobre la filosofía moral de Dworkin. Un rodeo por la metaética dworkiniana -o su confusión con la ética- nos permitirá saber hasta qué punto Dworkin merece o no del todo la etiqueta jusnaturalista que nuestro erizo, por lo demás, tampoco se esforzó por apartar de sí. 


\section{Coherencia metaética}

Y aquí es procedente acudir al coherentismo de Dworkin que es examinado por Lourdes Santos (pp. 408 ss), pero también Juan Manuel Pérez Bermejo, quien subraya que se trata de una respuesta al "arquimedismo", es decir, al error filosófico de buscar un único fundamento último a nuestros sistemas de creencias (p. 188). Para el resto de mortales distintos de Dworkin -aunque también David Gauthier exploraba un "Archimedian point" en su Morals by Agreement (Gauthier, 1988)_, "arquimedismo" es lo que habitualmente se conoce como "fundacionalismo" o, quizá mejor, "fundamentismo" - a falta de mejor alternativa a "fundamentalismo" que haría justicia a la definición del error de confiar todo nuestros sistemas de creencias en un presupuesto último (vid. Perona, 2003).

Pues bien, Pérez Bermejo nos ofrece una sugerente interpretación de la integridad dworkiniana a partir de las teorías de la coherencia. La integridad de un individuo o una institución es un valor o una virtud moral vinculada a la coherencia. Aplicada al Derecho, esto supone, a juicio de Pérez Bermejo, adoptar en primer lugar una visión holista del sistema jurídico; en segundo lugar, reconocerle un tipo de consistencia especial como es característica de los crucigramas, los puzzles, la red, la espiral que se abre cada vez en círculos más amplios o la balsa de Neurath, por usar algunas imágenes clásicas que nos indica Pérez Bermejo y entre las cuales encajaría la célebre metáfora de la novela en cadena de Dworkin (pp. $190 \mathrm{~s}$ ). En tercer lugar, la integridad incluye necesariamente un elemento pragmático, de modo que la integridad es un valor o una virtud que no puede ignorar la función que cumple el individuo o la institución llamada a ejercerla. El de Pérez Bermejo es, por cierto, un brillante ejemplo de lo que significa interpretar a su mejor luz un concepto tan central en Dworkin como el de la integridad.

La primera parte, sobre ética y metaética en Dworkin, aborda, en fin, la tesis dworkiniana de la difuminación de la frontera entre juicios metaéticos y éticos que promueve Dworkin con el fin de refutar el escepticismo moral (externo). Como es sabido, a juicio de Dworkin el escepticismo moral (una tesis metaética) en realidad siempre expresa un juicio moral (una tesis ética, de ética normativa). Se trataría en Dworkin de una consecuencia natural de que estamos "condenados a vivir dentro de la práctica de la moralidad" en palabras de Laporta (p. 31), quizá de que los humanos somos seres "estructuralmente morales" por reformularlo con Aranguren (1992: 110). Podríamos decir, en fin, que ser escépticos morales equivale a permitirlo todo si en algo valoramos la responsabilidad, otro concepto central para Dworkin. En este contexto, me parece procedente apuntar el punto de vista que Alchourrón y Bulygin expresan en Normative Systems, a propósito de la invalidez del principio de prohibición ("todo lo que no está prohibido, está permitido", i.e. "todo está prohibido o permitido") ${ }^{6}$. De esos maestros argentinos muchos -positivistas o no- aprendimos que la ausencia de calificación deóntica para una acción (permisión débil) no implica su permisión más genuina (permisión fuerte). Cabría objetar a Dworkin, por tanto, que la falta de calificación deóntica (o suspensión del juicio) a la que nos conduce el escepticismo no tiene por qué implicar una permisión en sentido fuerte. $\mathrm{Y}$, por cierto, es interesante advertir, dadas sus notorias diferencias, que tanto Dworkin como Kelsen sostienen más o menos expresamente el principio de prohibición y también la completitud del Derecho. Es de esta coincidencia precisamente de la que se ocupa Alberto del Real en su trabajo (pp. 483 ss).

En el primer bloque temático del volumen, tanto el artículo de Francisco Laporta como el siguiente de Ruiz Miguel abordan el estatus de la metaética

\footnotetext{
${ }^{6}$ Vid. Alchourrón y Bulygin (1971: 177 ss).
} 
dworkiniana de manera autónoma -no cabía esperar otra cosa- pero también hasta cierto punto complementaria. Laporta se concentra en el conocido ensayo de Dworkin "Objectivity and Truth: You'd Better Believe It" (Dworkin, 1996), mientras que Ruiz Miguel adopta una perspectiva más amplia, pero quizá también más crítica e incisiva. La objetividad moral dworkiniana se ubica para él en un "limbo" (p. 45) entre la objetividad científica y la subjetividad individual que a su juicio no tiene por qué ser incompatible con la posibilidad de desarrollar un genuino escepticismo externo frente a la moralidad. Temáticamente, la contribución de Óscar Pérez de la Fuente debería acompañar a las de Laporta y Ruiz Miguel pues su trabajo examina precisamente cómo la "objetividad interna" (Iglesias) y la tesis de la unidad de valor (p. 512) se opone tanto a la objetividad externa que presuntamente garantizarían hechos o mónadas morales (morones) como al pluralismo agonista de Berlin. Por su parte, Ruiz Miguel se lanza con precaución a reconstruir las tesis dworkinianas con nuevos conceptos que se suman a la exuberante imaginería conceptual de Dworkin (pp. $55 \mathrm{ss)}$ para concluir con una sencilla lección que a su juicio cabe extraer de la alambicada argumentación dworkiniana: "Olvídate del escepticismo metaético, pero no te creas infalible" (p. 68).

\section{Conclusión}

Este trabajo se ha servido de un amplio conjunto de contribuciones a El legado de Dworkin como hilo conductor para tratar de comprender un enigma: el de la irreconciliable disputa entre quienes, de acuerdo o no con Dworkin, reconocen en su obra un referente inexcusable de nuestro tiempo y quienes, a menudo sin polemizar directamente con él, rechazan cualquier valor jusfilosófico a su teoría. Pues bien, puede que El legado de Dworkin no resuelva del todo nuestras dudas, pero quizá sí nos ayude a disolverlas en buena medida. $Y$ las disuelve porque el enigma está basado en un equívoco sobre el propio valor de la reflexión jusfilosófica. Ese valor nunca radica exclusivamente en las propiedades intrínsecas de una teoría, sino también y sobre todo en su capacidad para estimular y encender una dialéctica. Una vez comprendido esto, creo que si algo cabe aprender de las contribuciones a El legado de Dworkin es que su teoría supo llenar de energía una reflexión, la jusfilosófica, fuertemente expuesta al languidecimiento y la decadencia. En el peor de los casos -y por más paradójico que parezca- muchas veces debemos atender a una teoría sospechosa de falta de valor para ser conscientes del valor profundo de nuestra propia investigación.

Bibliografía

ALCHOURRÓN, C.E. y BULYGIN, E. (1975), Introducción a la metodología de las ciencias jurídicas y sociales, Astrea, Buenos Aires.

ARANGUREN, J.L.L. (1992), Ética de la felicidad y otros lenguajes, Tecnos, Madrid.

BELTRÁN DE FELIPE, M. (1989) Originalismo e intepretación. Dworkin vs. Bork. Una polémica constitucional, Civitas, Madrid.

CALSAMIGLIA, A. (1984), "Ensayo sobre Dworkin". En:, R. DWORKIN, Los derechos en serio, trad. M. Guastavino, Ariel, Barcelona, pp. 7-29.

CANO, ZAMORA y GUZMÁN (2007). "Riggs contra Palmer. Tribunal de Apelaciones de Nueva York-115 NY 506", Revista telemática de filosofía del derecho (RTFD), núm. 11, 40, disponible en la siguiente dirección electrónica: www.rtfd.es, fecha de consulta: 20 de septiembre de 2016.

DUMMETT, M. (1993), Origins of Analytical Philosophy, Harvard University Press, Cambridge (Massachussets).

DWORKIN, R. (1984), Los derechos en serio, trad. M. Guastavino, Ariel, Barcelona. DWORKIN, R. (1992), El imperio de la justicia, trad. C. Ferrari, Gedisa, Barcelona.

DWORKIN, R. (1996), “Objectivity and Truth: You'd Better Believe It”. En: Philosophy 
and Public Affaires, vol. 25, 2, pp. 87-139.

DWORKIN, R. (2014), Justicia para erizos, Fondo de Cultura Económica, México.

GARCÍA FIGUEROA, A. (1998), Principios y positivismo jurídico. El no positivismo principialista en las teorías de Ronald Dworkin y Robert Alexy, Centro de Estudios Políticos y Constitucionales, Madrid.

GARCÍA FIGUEROA, A. (2016), "Comentario a J.M. Sauca (ed.), El legado de Dworkin a la filosofía del derecho. Tomando en serio el imperio del erizo", Revista de Estudios Políticos, abril-junio , pp. 257-265.

GAUTHIER, D. (1988), Morals by Agreement, OUP, Oxford.

HABA, E.P. (2011), "El bluff Dworkin. Su rehabilitación del no-saber en la actual Teoría del Derecho (Retorno al realismo ingenuo y apogeo del Efecto Vicente, lanzados por una reencarnación del Prof. Beale)", Criterio jurídico, vol. 9, núm. 1, pp. $155-258$.

IGLESIAS VILA, M. (1999), El problema de la discreción judicial, Centro de Estudios Políticos Constitucionales, Madrid.

LAPORTA, F. (2007), El imperio de la ley. Una visión actual, Trotta, Madrid.

LORA, P. de, (1998), La interpretación originalista de la Constitución. Una aproximación desde la filosofía del derecho, Centro de Estudios Políticos y Constitucionales, Madrid.

MORESO, J.J., PRIETO, L. y FERRER, J. (2010), Los desacuerdos en el Derecho, Fundación Coloquio Jurídico Europeo, Madrid.

PERONA, A. (2003), voz "fundament(al)ismo". En: J. Muñoz (coord.), Diccionario filosófico, Espasa, Madrid, 2003, pp. 362-365.

SAUCA, J.M. (2015), El legado de Dworkin a la filosofía del derecho. Tomando en serio el imperio del erizo, Centro de Estudios Políticos y Constitucionales, Madrid.

SOUZA SANTOS, B. de (2005), El milenio huérfano. Ensayos para una nueva cultura política, Trotta, Madrid. 